\title{
Ensinar e aprender no meio virtual: rompendo paradigmas
}

Gillberto Lacerda dos Santos

Universidade de Brasília

\section{Resumo}

Este texto relata os resultados de uma pesquisa de síntese desenvolvida no período entre 2004 e 2008, a partir de 13 dissertações de mestrado acadêmico e profissionalizante, com o objetivo de discutir a sala de aula virtual. Mais precisamente, o texto procura configurar a crise paradigmática em torno da ruptura entre a sala de aula presencial e a sala de aula virtual, tendo em vista a emergência da sociedade da informação, por meio de dados empíricos coletados pelos 13 mestrandos participantes da pesquisa longitudinal financiada pelo CNPq, pela FAPDF e pela FENADESP. Na primeira parte, há uma introdução geral ao tema e à problemática de pesquisa que deram origem à investigação meta-analítica ou de síntese aqui desenvolvida, configurada por quatro questões: 1) quais são os novos formatos para a sala de aula virtual?; 2) quais estratégias pedagógicas mostram-se adequadas para nortear o trabalho docente na sala de aula virtual?; 3) quais materiais didáticos inovadores são condizentes com o trabalho docente na sala de aula virtual?; 4) quais novos papéis docentes surgem no contexto da sala de aula virtual? Logo em seguida, há uma descrição sucinta da abordagem metodológica adotada para subsidiar nosso esforço investigativo em busca de respostas às questões de pesquisa anunciadas. A terceira parte consiste em um quadro teórico, igualmente sucinto, acerca do conceito de sala de aula virtual. No item seguinte, há a discussão de cada questão à luz dos resultados alcançados nas 13 dissertações de mestrado analisadas. Por fım, são elaboradas algumas conclusões finais, as quais apontam e discutem certos elementos definidores da sala de aula virtual que configuram a referida crise paradigmática.

\section{Palavras-chave}

Sala de aula virtual - Novas tecnologias de informação - Comunicação e expressão - Escola - Moodle. 


\section{Teaching and learning in the virtual environment: shifting paradigms}

Gilberto Lacerda dos Santos

University of Brasilia

Contact:

Gilberto Lacerda dos Santos

UnB - Faculdade de Educação

Campus Universitário Darcy Ribeiro

70910-900 - Brasília/DF

E-mail: glacerda@unb.br

\begin{abstract}
This text describes the results of a synthesis study developed during the period between 2004 and 2008, based on 13 academic and professional Master dissertations, with the objective of discussing the virtual classroom. More precisely, the text aims at outlining the paradigm crisis around the rupture between the presence classroom and the virtual classroom, in view of the emergence of the information society, through empirical data gathered by the 13 Master students that took part in this longitudinal study sponsored by CNPq, FAPDF, and FENADESP. In its first part, there is a general introduction to the theme and to the research problem that gave origin to the meta-analytic or synthesis study described here, which is defined by four questions: 1) what are the new formats for the virtual classroom?; 2) what pedagogical strategies are more adequate to guide the teaching work in the virtual classroom?; 3) what innovative didactic materials are consistent with the teaching work in the virtual classroom?; 4) what new teacher roles emerge in the context of the virtual classroom? There follows a succinct description of the methodological approach adopted to give support to our investigation effort in search of answers to the questions posed above. The third part of the article consists of an equally brief theoretical picture of the concept of virtual classroom. The next section brings a discussion of each of those issues in the light of the results achieved in the 13 Master dissertations analyzed. Lastly, conclusions are put forward, which point out and discuss some of the defining elements of the virtual classroom that give shape to the paradigm crisis alluded to here.
\end{abstract}

\section{Keywords}

Virtual classroom - New information technologies - Communication and expression - School - Moodle. 
As novas possibilidades de ensino e de aprendizagem no meio virtual apresentam uma série de desafios e de questões que constituem objeto de investigação de pesquisadores em todo o mundo. Além disso, entender o modo de funcionamento das relações educativas que são delimitadas pelas novas tecnologias de informação, comunicação e expressão (NTICE) é uma preocupação presente em cada professor que, nestes tempos de emergência da chamada sociedade da informação, tem a responsabilidade de promover, junto a seus alunos, aprendizagens significativas, pertinentes e contextualizadas em um ambiente societário tão dinâmico quanto a própria internet. Seja como objeto de investigação teórica ou de preocupação empírica, desvendar os processos de ensino-aprendizagem no meio virtual é crucial para a invenção de uma nova escola, baseada em uma nova organização do trabalho pedagógico, suscetível a possibilitar o entorno educativo necessário para que a sala de aula possa continuar, de forma renovada, a cumprir sua missão. Nesse sentido, procuramos identificar, mediante a realização de 13 dissertações de mestrado agrupadas em torno de uma pesquisa longitudinal iniciada em 2004 e concluída em 2008, respostas para quatro questões referentes ao rompimento de paradigmas no processo de ensino e de aprendizagem no meio virtual:

1- Quais são os novos formatos para a sala de aula virtual?

2- Quais estratégias pedagógicas mostram-se adequadas para nortear o trabalho docente na sala de aula virtual?

3- Quais materiais didáticos inovadores são condizentes com o trabalho docente na sala de aula virtual?

4- Quais novos papéis docentes surgem no contexto da sala de aula virtual?
Essas quatro questões delimitaram o desenvolvimento de um conjunto de dissertações de mestrado no período entre 2004 e 2008, as quais forneceram diversos elementos de resposta para que avancemos na discussão e na compreensão dessa problemática. A dissertação de mestrado de Maísa Pieroni (2004), sobre comunidades de aprendizagem em rede; a de Aisha Paulo Fonseca (2005), sobre a internet como meio de comunicação pedagógica de conteúdos dinâmicos; a de Marcelo Minholi (2007), sobre o oferecimento de cursos em ambiente virtual de aprendizagem; e a de Woquiton Fernandes (2007), sobre aprendizagem colaborativa em rede por meio do Moodle, foram articuladas em torno da primeira questão: quais são os novos formatos para a sala de aula virtual?

A dissertação de Wanessa de Castro (2008), sobre a pedagogia de projetos como estratégia para uso da informática na educação; a de Cleovane Raimunda de Souza (2007), também sobre a relação entre pedagogia de projetos e informática educativa; e a de Marcelo Akira Inuzuka (2008), sobre o uso do wiki na educação, buscaram respostas para a segunda questão: quais estratégias pedagógicas mostram-se adequadas para nortear o trabalho docente na sala de aula virtual?

A dissertação de André Luiz César Ramos (2004), sobre a transposição de textos em hipertextos; a de Eliã Siméia Amorim (2007), sobre a internet como meio de ensino, aprendizagem e divulgação científica; e a de Rafael Lacerda (2007), sobre o desenvolvimento de softwares educativos, foram desenvolvidas em torno da terceira questão: quais materiais didáticos inovadores são condizentes com o trabalho docente na sala de aula virtual?

Por fim, a dissertação de Valéria Kneipp Sena (2004), sobre a mediação pedagógica em situação de videoconferência, e as de Mirela Malvestiti (2004) e de Jaqueline Ferraz de Andrade (2007), sobre a mediação na tutoria on-line, 
foram desenvolvidas tendo como eixo central a quarta questão: quais novos papéis docentes surgem no contexto da sala de aula virtual?

É claro que as investigações realizadas no contexto dessas 13 dissertações não esgotam a problemática, que tem diversas outras facetas ligadas à integração das NTICE na escola, as quais tampouco devem ser vistas como o único fator suscetivel de provocar as mudanças educacionais almejadas por toda a sociedade. Empregando métodos distintos em torno de objetos de pesquisa igualmente complementares, os trabalhos desses 13 orientandos de mestrado apontam para um cenário incontornável no que se refere aos processos tradicionais de comunicação de conhecimentos às novas gerações por meio de situações formais de ensino e de aprendizagem: não é mais possível conceber a escola sem uma abertura ampla para o emprego pedagógico das novas tecnologias de informação, comunicação e expressão, sob pena de torná-la sem pertinência social e desprovida de sentido coletivo e individual no contexto da sociedade tecnológica emergente.

Tal premissa é, entretanto, portadora de uma situação problemática ainda em aberto e que preocupa tanto teórica, quanto empiricamente, pesquisadores e professores em toda parte: como integrar as NTICE no contexto de uma escola que ainda é igual à de 50 ou 100 anos atrás, e que continua a funcionar alicerçada em planos de aula pré-estabelecidos, em conhecimentos pré-mapeados, em didáticas caducas e em grades curriculares que fazem jus ao seu nome, aprisionando ao invés de libertarem? Indicar pistas de solução para essa problemática é justamente o objetivo da investigação aqui relatada.

\section{Abordagem metodológica: a pes- quisa de síntese}

Esta investigação de síntese ou meta-analítica (PETITTI, 1994) foi conduzida, ao longo de cinco anos, por meio de uma abordagem meta-cognitiva alicerçada nas problemáticas de pesquisa das 13 dissertações de mestrado mencionadas no item anterior, nas quais dados empíricos foram coletados e analisados sob nossa orientação acadêmica e alinhados em torno do mesmo projeto integrado de pesquisa. Em outros termos, cada dissertação de mestrado aqui considerada contribuiu, de forma distinta e complementar, para que avançássemos na elucidação de questões mais amplas. Em duas outras oportunidades, já havíamos utilizado processos de orientação acadêmica como instrumentos de pesquisa e de coleta de dados para subsidiar iniciativas de meta-análise (LACERDA SANTOS, 2006a, 2006b). Nessas duas investigações, as problemáticas abordadas pelos alunos-pesquisadores foram estrategicamente articuladas em torno de questões mais amplas, o que gerou procedimentos de investigação-colaborativa sob a forma de projetos integrados de pesquisa. É evidente que, considerando o papel dos atores envolvidos no procedimento (orientador e orientandos), a abordagem meta-analítica adquire contornos de pesquisa-participante, na qual as três dimensões apontadas por Teresa Maria Haguette (1985) são bastante claras, por se tratar de: a) um processo concomitante de geração de conhecimento entre todos os participantes; b) um processo educativo, que busca a intertransmissão e o compartilhamento dos conhecimentos; c) um processo de mudança, seja aquela que ocorre durante a pesquisa, à qual preferimos chamar de mudança imediata, seja aquela projetiva, que extrapola o âmbito e a temporalidade da pesquisa, na busca de transformações estruturais práticas que favoreçam os atores envolvidos na investigação. No caso da pesquisa meta-analítica aqui descrita, o trabalho de síntese perpassou 13 problemas de pesquisa e 13 procedimentos metodológicos distintos, todos girando em torno do mesmo objeto, aqui percebido na perspectiva do rompimento de paradigmas ao se ensinar e aprender no meio virtual, tema do quadro teórico apresentado a seguir. 


\section{Um breve quadro teórico sobre a sala de aula virtual}

Pierre Lévy (1995), em seu visionário livro $O$ que é o virtual?, tece as seguintes considerações acerca do conceito de ciberespaço, definido como o ambiente da virtualidade:

No limite, só há hoje um único computador, um único suporte para texto, mas tornou-se impossível traçar seus limites, fixar seu contorno. É um computador cujo centro está em toda parte e a circunferência em nenhuma, um computador hiper-textual, disperso, vivo, pululante, inacabado, virtual, um computador de Babel: o próprio ciberespaço. [...] No ciberespaço, como qualquer ponto é diretamente acessável a partir de qualquer outro, será cada vez maior a tendência a substituir as cópias de documentos por ligações hiper-textuais: no limite, basta que o texto exista fisicamente uma única vez na memória de um computador conectado à rede para que ele faça parte, graças a um conjunto de vínculos, de milhares ou mesmo de milhões de percursos ou de estruturas semânticas diferentes. (p. 47)

No contexto dessas conjecturas, o autor desenvolve a ideia de que o virtual não é o oposto do real, como se tende a crer. Há, pelo contrário, toda uma realidade concreta nas interações e ações realizadas no ciberespaço, nesse ambiente imaterial constituído por informações de toda natureza, interligadas e intercomunicantes, suscetiveis de modificarem a própria estrutura do pensamento humano. Apesar de sua concretude inquestionável, o ciberespaço ou espaço virtual é o ambiente imaterial constituído pelos milhões de pessoas - e não de computadores - de todo o mundo, interligados em rede por meio da internet. E é nesse espaço que novas manifestações societárias acontecem e evoluem.
0 primeiro pesquisador a utilizar o termo ciberespaço para designar o meio virtual foi Willian Gibson (1991), que, já no início dos anos 1990, anunciava que o espaço virtual estava em vias de globalização e já constituía um espaço social de trânsito inevitável para milhões de pessoas. Desde então, muitos outros autores têm se dedicado a desbravar e a entender o meio virtual, como o próprio Lévy (1993, 1995), para quem o virtual é um meio em que será possível consolidar a tecnodemocracia, ou seja, uma nova formação política na qual a tecnologia da eletrônica tornará viável o desenvolvimento de comunidades inteligentes capazes de se autogerir; André Lemos (1998), para quem a exploração do ciberespaço é uma forma de contracultura e a internet, em breve, será percebida como uma infraestrutura banal, como as redes de água, luz ou telefone; Manuel Castells (1999), que aponta o meio virtual como ferramenta indispensável para a implantação efetiva dos processos de reestruturação socioeconômica e para a formação de redes como modo dinâmico e autoexpansível de organização da atividade humana; Nicholas Negroponte (1995), que já previa, nos anos 1990, que a comunidade de usuários da internet ocuparia o centro da vida cotidiana e que sua demografia iria ficar cada vez mais parecida com a do próprio mundo.

No campo da educação, as repercussões da emergência desse mundo virtual, proveniente das redes globais de computadores, são bastante óbvias. Sobretudo, se considerarmos que o principal papel da educação reside na preparação do indivíduo para, autonomamente, saber buscar informações e transformá-las nos conhecimentos de que ele necessita, no momento em que deles necessita e da forma mais criativa possível.

Nessa perspectiva, a escola tradicional de funcionamento linear, alicerçada em materiais didáticos estáticos e centrada na ação e no 
conhecimento do professor, não subsiste mais incólume. Em face do movimento avassalador, que ocorre na sociedade como um todo, há um amplo mal-estar instaurado no ambiente escolar, cujas dinâmicas de ensino e aprendizagem não integram princípios fundamentais da sociedade da informação, tais como: a autonomia, a independência na busca de conhecimentos, a capacidade de autoformação, o pensamento hipertextual, a criatividade, entre outros. Tais princípios demandam um modo de funcionamento rizonômico, alicerçado em materiais didáticos dinâmicos e centrado na ação e no conhecimento de todos os atores da relação educativa e, sobretudo, na responsabilização do aluno pelo seu próprio processo de construção de saberes. Dentre muitos e muitos pesquisadores, a compreensão dos meandros das relações educativas no mundo virtual é objeto de pesquisa de autores como Starr Roxanne Hiltz (1995), que foca sua atenção nas novas possibilidades de aprendizagem colaborativa em rede; Michael Moore (1993), que, no campo da educação não presencial, propõe a teoria da distância transacional; Linda Harasim et al. (2005), que buscam revelar como as tecnologias de comunicação mediada por computador - correio eletrônico, bulletin boards, sistemas de conferência e internet - podem ser utilizadas nos ensinos fundamental, médio e universitário, bem como na educação de adultos; Otto Peters (2006), que procura estabelecer as bases de uma didática do ensino virtual; Rena Palloff e Keith Pratt (2005), que têm como objeto de investigação as relações estabelecidas entre alunos e conhecimentos em dinâmicas de educação mediadas por tecnologias. No cenário acadêmico brasileiro, podemos citar nomes tais como Vani Kenski (2003), que se dedica a discutir os suportes tecnológicos e as ações docentes em situação de educação a distância; Marco Silva (2000), que busca situar o hipertexto e as tecnologias digitais na nova sala de aula; Raquel Barreto (2002), que preocupa-se com a formação de professores para atuar na sala de aula virtual; Elsa Guimarães Oliveira (2003), que discute justamente a mudança paradigmática na educação decorrente da influência das tecnologias digitais; Maria Luiza Belloni (2005), que introduz e debate o conceito de mídia-educação; Nelson de Luca Pretto (1996), que discute o futuro da escola na sociedade da informação; Ângela Álvares Dias (2007), que aponta as possibilidades educativas múltiplas e inovadoras do hipertexto; e Raquel de Almeida Moraes (2003), que defende a exploração educativa do ciberespaço por meio de uma pedagogia libertadora. De nossa parte, também nos associamos a esses pesquisadores e defendemos a adoção de um novo modo de formação de professores (F2) em oposição aos modos tradicionais de formação docente (F1), como caminho crucial para preparar novas gerações de profissionais da educação que atuem adequadamente no contexto da escola da sociedade digital emergente (LACERDA SANTOS, 2005).

De modo geral, os trabalhos desses pesquisadores, tanto os estrangeiros, quanto os brasileiros, lançam luzes sobre as importantes questões da mudança de dinâmica da escola no meio digital, dos novos papéis de alunos e de professores nas relações educativas virtuais, da organização do trabalho pedagógico em tais situações. Também enfatizam o surgimento de novos paradigmas, necessários para que haja uma aproximação maior entre o que se passa na escola e o que se passa fora dela. Sobretudo, os autores indicam que há muito mais perguntas do que respostas e que estamos no meio de um processo de crise paradigmática, como avaliaria Thomas Kuhn (1970), na qual alunos e professores esbarram na mesma fronteira: a da exploração pertinente e significativa das NTICE. As pistas de pesquisa que emergem desse quadro teórico, extremamente resumido, são inquestionavelmente importantes, sobretudo quando se têm em mente informações há pouco divulgadas, decorrentes de investigações acadêmicas, 
relatando que ao longo dos últimos anos não se têm alcançado resultados significativos com o uso de tecnologias na escola; que o computador e a internet na sala de aula não têm melhorado nem a qualidade do ensino, nem os processos de aprendizagem; que a informática na educação é mais um problema que uma solução (CASTRO, F., 2008; DWYER et al., 2007). Tais resultados, ao invés de apontarem para trás, para um retrocesso, apontam para frente, para a necessidade do avanço. Eles evidenciam a crise paradigmática instaurada na escola e a necessidade de inventar uma nova escola, mais articulada com tecnologias, linguagens, estratégias e possibilidades de informação, comunicação e expressão que, inelutavelmente, caracterizam a sociedade que acolhe a escola, a qual não pode permanecer como se fosse um peixe em um aquário, protegido da água por uma bolha de plástico: debatendo-se sem possibilidades de renovação do ar.

Considerando o exposto, e enfatizando que a adoção das NTICE não implica, necessariamente, uma transformação qualitativa da escola, as questões de pesquisa que delimitam a investigação longitudinal aqui relatada serão retomadas a seguir, à luz de considerações elaboradas a partir dos resultados obtidos pelas 13 dissertações de mestrado por meio das quais dados empíricos foram coletados e analisados. É importante sinalizar que nosso objetivo neste texto é configurar o processo de integração das NTICE na educação, o que nos conduzirá à adoção de novas práticas pedagógicas e à invenção de uma nova escola, condizente com os parâmetros e modos de funcionamento da sociedade da informação.

\section{Questão 1: Quais são os novos forma- tos para a sala de aula virtual?}

Interrogar-se sobre a formatação da sala de aula virtual corresponde a uma das dimensões mais contundentes dessa virada paradigmática. Como professores, necessitamos entender de que modo as NTICE afetam nosso trabalho e oferecem-nos novas possibilidades de intervenção didática, menos hierarquizadas, com menos foco no professor, baseadas em uma dinâmica de aprendizagem com ênfase no grupo, na rede de interações que pode ser estabelecida e na construção coletiva de saberes. Explorando a principal característica das redes digitais, verifica-se que o formato de comunidades de aprendizagem em rede, nas quais alunos e professores interagem rizonomicamente, é o que mais tem logrado sucesso nas experiências de educação on-line.

A investigação de Pieroni (2004) examina o modo de funcionamento de comunidades de aprendizagem em rede corporativa e revela o quanto a sala de aula virtual pode ser abrangente, inclusiva, romper fronteiras e, efetivamente, reelaborar conhecimentos e promover aprendizagens individuais efetivas a partir de processos cognitivos coletivos. Por outro lado, Fonseca (2005) conseguiu mostrar que a natureza dinâmica da internet requer conteúdos dinâmicos e relações educativas igualmente dinâmicas, as quais evoluem de acordo com o avanço dos conhecimentos, com o nível cognitivo dos atores e com as possibilidades tecnológicas disponibilizadas. Esse formato de comunidade de aprendizagem em rede, com foco na dinamicidade dos conteúdos e processos, encontra excelente espaço de viabilização nos ambientes virtuais de aprendizagem (AVA). De fato, nos AVAs, a sala de aula virtual é pré-formatada, gira em torno de atividades síncronas e assíncronas as mais diversas, explora diferentes canais de comunicação (chats, fóruns, listas etc.) e permite que todos os intervenientes atuem sobre o conteúdo. É o que demonstraram Minholi (2007) e Fernandes (2007) em seus trabalhos de investigação sobre, respectivamente, o uso do AVA Moodle em educação a distância e o estabelecimento de redes de aprendizagem colaborativa. Assim sendo, essas quatro dissertações apontam a comunidade de aprendizagem em rede como um excelente formato a 
ser explorado na instauração da sala de aula virtual. Para tanto, é importante considerar sua capacidade de: agregar dinâmica e qualitativamente os atores da relação educativa; fornecer continuamente interatividade e retroação; diminuir a distância transacional; permitir acompanhamento avaliativo tanto formativo, quanto somativo; manter a memória das interações; agregar diferentes linguagens tecnológicas e servir a situações de intermitência entre ensino presencial e ensino não presencial. É igualmente importante considerar sua maleabilidade no que se refere ao trabalho docente, o que permite a adoção de múltiplas estratégias pedagógicas, tema do próximo conjunto de dissertações.

\section{Questão 2: quais estratégias peda- gógicas mostram-se adequadas para nortear o trabalho docente na sala de aula virtual?}

Há duas dificuldades em identificar estratégias pedagógicas condizentes com a natureza do ambiente educativo proporcionado pela sala de aula virtual. Por um lado, há a maleabilidade do próprio meio virtual, em que as tecnologias são meras ferramentas inertes, cujo desempenho depende da ação do professor. Por outro lado, há a natureza do próprio trabalho pedagógico em um ambiente qualitativamente diferente por ser virtual, interativo, hipertextual e dinâmico. Na busca de estratégias pedagógicas capazes de superar essas dificuldades e de valorizar o aluno em seu processo de aprendizagem, bem como o professor em seu processo de ensino, Wanessa de Castro (2008) investiu na pedagogia de projetos como estratégia adequada para nortear o trabalho docente na sala de aula virtual. A pesquisadora constatou que essa estratégia proporciona aos sujeitos envolvidos na relação educativa não presencial interações condizentes com as características desse novo ambiente, as quais exploram a multiplicidade de linguagens, a horizontalidade nas interações, a diferença de ritmos de aprendizagem e de estilos cognitivos. A investigação assinalou também que a pedagogia de projetos resgata o interesse dos alunos pela escola, pela aprendizagem e pela construção de conhecimentos, possibilitando o desenvolvimento da autonomia, da criticidade e da autoconfiança. Souza (2007) avançou na mesma direção, enfatizando, todavia, a criatividade. A pesquisadora investigou o uso pedagógico do computador como vetor das habilidades do comportamento criativo em crianças que estão no ensino fundamental em situação de aprendizagem mediada por computadores, por meio da pedagogia de projetos. Os resultados positivos alcançados reforçaram o potencial didático da pedagogia de projetos para uso na sala de aula virtual. Sempre na busca de respostas para a questão de pesquisa em foco, orientamos a dissertação de mestrado de Inuzuka (2008), que investigou o uso do wiki como vetor constitutivo de relações educativas na sala de aula virtual. Sendo o wiki um dispositivo que permite a edição coletiva de documentos em ambientes de desenvolvimento colaborativo na internet, a investigação girou em torno de um estudo de caso em que estudantes de pedagogia da Faculdade de Educação da Universidade de Brasília foram envolvidos em uma atividade didática colaborativa em rede. A sala de aula virtual tomava os estudantes como alunos e o pesquisador como professor. As observações então realizadas reforçaram o poder da colaboração e da interatividade como fatores educativos incontornáveis no meio virtual.

A partir de tais investigações, não é possível indicar uma estratégia pedagógica em particular para delimitar o trabalho na sala de aula virtual, mas é possível apontar a colaboração, a horizontalização e a interatividade como premissas básicas de qualquer estratégia que venha a ser empregada. Efetivamente, a sala de aula virtual, por não contar com seus atores em 
situação de presença física e tendo à sua disposição as possibilidades de uma comunidade de aprendizagem em rede, responsabiliza cada um por sua própria participação produtiva na relação educativa, o que os faz colaborar para progredir e atingir plenamente os objetivos de aprendizagem, compartilhar a tarefa de ensinar e o papel docente, e interagir, do modo mais amplo possível, para construir conhecimentos e usufruir dos materiais didáticos disponibilizados. Aliás, é importante sinalizar que há uma conexão cervical entre as estratégias de aprendizagem e os materiais didáticos empregados em relações educativas virtuais. Foi justamente pensando nessa conexão entre estratégias pedagógicas e materiais didáticos que as dissertações comentadas a seguir foram desenvolvidas.

\section{Questão 3: Quais materiais didáticos inovadores são condizentes com o tra- balho docente na sala de aula virtual?}

Tanto quanto as estratégias pedagógicas, os materiais didáticos têm um papel fundamental na consolidação da sala de aula virtual. É muito comum vermos situações de ensino-aprendizagem inovadoras, calcadas na virtualidade, empregando materiais didáticos tradicionais, o que desvirtua, sem trocadilhos, as relações educativas almejadas ou alardeadas. 0 desenvolvimento de materiais didáticos para a sala de aula virtual - objetos de aprendizagem, conteúdos digitais, hiperdocumentos, sites educativos, blogs etc. - constitui, portanto, uma necessidade fundamental para subsidiar o trabalho docente em situações de exploração pedagógica das NTICE. Apesar de seu amplo reconhecimento, essa necessidade não tem encontrado respaldo nos cursos de formação de profissionais da educação que, desprovidos de competências relacionadas com o desenvolvimento desses materiais didáticos, tornam-se usuários passivos dos meios tecnológicos. De fato, por falta de formação adequada, os professores distanciam-se de uma atuação mais empreendedora nesse campo e não se envolvem na concepção de seus próprios materiais didáticos, deixando tal tarefa para profissionais de outras áreas que, por sua vez, não têm o conhecimento e a prática requeridos acerca do fenômeno educativo. Certamente, temos nesse cenário um dos problemas que mais dificultam a exploração das tecnologias digitais na escola, que inviabilizam a implantação da sala de aula virtual, tal qual preconizada pelos teóricos da área, e que produzem resultados negativos ou pífios, quando se avalia a aprendizagem decorrente de situações de ensino baseadas nessas tecnologias. A área do desenvolvimento de materiais didáticos para a sala de aula virtual é bastante ampla e plena de possibilidades não exploradas, permanentemente enriquecidas pelos avanços tecnológicos quase cotidianos.

As dissertações de mestrado de Ramos (2004), que analisa o processo de transposição de textos em hipertextos; de Amorim (2007), que aborda o uso da internet como material didático; e de Lacerda (2007), que propõe uma abordagem para o desenvolvimento de softwares educativos, apenas percorrem perpendicularmente esse campo totalmente em aberto para profissionais da educação e indicam pistas de pesquisa e de desenvolvimento que precisam ser consideradas. 0 trabalho de Ramos (2004) é muito interessante e responde a uma grande demanda da área: como transformar, modificar e adaptar materiais didáticos e conteúdos tradicionais para uso na sala de aula virtual? A partir de um texto paradidático de apoio ao ensino da geometria plana, o pesquisador desenvolve e propõe um método para a construção de um hipertexto educativo, mantendo a mesma matriz didática e a intencionalidade original do autor, mas agregando, todavia, diversas possibilidades de interatividade, leitura não linear, percursos alternativos e links enriquecedores. Ramos demonstra, por meio de sua investigação, que há 
uma distância enorme entre a dinâmica dos materiais didáticos estáticos e a dos materiais didáticos dinâmicos requeridos pela sala de aula virtual. Demonstra também que só é possivel ir na direção desses últimos a partir de um conhecimento amplo do conceito de interatividade e da percepção da relação educativa aberta proposta pelo meio virtual como uma situação de liberdade, de criatividade, de autonomia e de recriação cognitiva permanente.

Esses mesmos princípios podem ser encontrados nas entrelinhas dos resultados alcançados por Amorim (2007) em seu trabalho sobre o uso da internet como material didático, mais especificamente como dispositivo de ensino da geografia, acolhendo um museu virtual. Esse trabalho corrobora a ideia de que o formato e a natureza da sala de aula virtual demandam materiais didáticos autoatualizáveis, que miram na capacidade de o aluno transitar mais livremente entre sua própria cognição, as trilhas propostas pelo material didático e a intencionalidade didática do professor. Trata-se de uma situação de grande complexidade - é necessário enfatizar que acentua o papel do docente em sua tarefa de atribuir significados, estabelecer sentidos e, dentro do espaço rizonômico da sala de aula virtual, promover a realização de objetivos de aprendizagem.

Para tanto, é necessário que esse material didático digital seja desenvolvido de acordo com princípios, critérios e procedimentos distintos daqueles empregados no desenvolvimento de materiais didáticos convencionais. É justamente isso o que preconiza a investigação realizada por Lacerda (2007), que propõe uma abordagem específica para a análise de requisitos quando do desenvolvimento de softwares educativos. 0 modelo de análise de requisitos proposto pelo pesquisador, denominado helicoidal, evidencia a necessidade de considerar não apenas as características do público-alvo do objeto de aprendizagem, como também o contexto da relação educativa que o empregará e, ainda, a natureza do conteúdo pedagógico a ser proposto aos alunos. Esse conjunto de investigações, a despeito de indicarem princípios e critérios para o desenvolvimento de materiais didáticos condizentes com o trabalho docente na sala de aula virtual, também enfatizam o quanto se torna complexa a atuação do professor nesse ambiente. Assim sendo, apesar da excessiva recorrência desse tema entre os pesquisadores da área, o que conduz a uma certa fadiga epistemológica no campo, voltamos a acolher propostas de investigação em torno dos novos papéis docentes em situações de ensino alicerçadas em NTICE, objeto da quarta e última questão de nosso projeto integrado de pesquisa.

\section{Questão 4: Quais novos papéis docen-} tes surgem no contexto da sala de aula virtual?

As relações educativas no meio virtual acontecem de modo estruturalmente similar àquelas que ocorrem na sala de aula tradicional: envolvem interações epistemológicas formais entre alunos, professores e saberes; são definidas por objetivos de aprendizagem claramente estabelecidos, pela exploração de materiais didáticos especialmente escolhidos ou desenvolvidos e pelo emprego de estratégias pedagógicas que o professor julga adequadas para promover a construção de conhecimentos junto aos alunos. No entanto, as relações educativas virtuais são conjunturalmente diferentes, tendo em vista sua cartografia rizomática, sua ecologia interativa, polifônica e polissêmica, e sua pedagogia da colaboração, promotora de uma inteligência coletiva (LÉVY, 1993). Assim, a dinâmica preconizada para a sala de aula virtual tem como um de seus princípios básicos uma reconceituação do sujeito em processo de aprendizagem, decididamente entendido não mais como consumidor de conteúdos prontos, mas como coautor e coprodutor de tais 
conteúdos, o que implica, necessariamente, a emergência de novos papéis docentes (MACIEL, 2002).

Procurando avançar no estudo e na compreensão desses novos papéis do professor na sala de aula virtual, orientamos o desenvolvimento de três dissertações de mestrado sobre duas situações educativas virtuais diferentes: a videoconferência (SENA, 2004) e o ensino pela internet (MALVESTITI, 2004; ANDRADE, 2007). A pesquisa realizada por Sena (2004) mostrou que, se a atuação do professor já privilegia o diálogo, a flexibilidade, a interação e a motivação constante dos alunos, estamos diante de um professor com credenciais de sucesso em qualquer ambiente educativo, incluindo o virtual. Entretanto, se o professor privilegia a aula expositiva, na qual somente ele fala e os alunos escutam, ele está fadado a uma situação insustentável de falta de comunicação com seus próprios alunos. Já os trabalhos de Malvestiti (2004) e de Andrade (2007) foram diretamente focados na mediação pedagógica em situação de educação não presencial e tiveram como âncora a ação tutorial. A primeira pesquisadora, sob nossa orientação, consultou 35 tutores de um curso virtual acerca dos requisitos para ser um bom tutor. Ela obteve 22 indicações, dentre as quais a capacidade de autoaprendizagem, a constância da presença virtual, a persistência, o conhecimento do conteúdo e das ferramentas digitais, e a sensibilidade para perceber as necessidades dos alunos, o que é fundamental no combate da distância transacional. Por sua vez, Andrade (2007) constatou que, em processos educativos a distância, os instrumentos de comunicação transformam-se em instrumentos simbólicos de mediação, por meio dos quais o sujeito constrói seu raciocínio, dinamiza múltiplas habilidades e potencializa suas linguagens. 0 exercício da mediação pedagógica em tal contexto demanda um tutor ou professor capaz de potencializar a autonomia, a motivação para aprender e as singularidades de um processo que se constrói pela interatividade do grupo. Em consequência, os novos papéis docentes na sala de aula virtual são, sobretudo, aqueles relacionados com a gestão de situações educativas virtuais, descentralizadas, geograficamente dispersas, sem a perda dos fios condutores, os quais devem conduzir os alunos à conclusão das interações e à realização dos objetivos de aprendizagem previstos, fazendo com que se sintam conectados e em permanente atividade de trabalho.

\section{Considerações finais}

Os percursos investigativos realizados por esses 13 pesquisadores apontam elementos de resposta concretos para as questões de pesquisa formuladas. Tais respostas colocam-nos diante de uma última indagação, a qual concluiu a abordagem do tema proposto neste texto: quais paradigmas devem ser rompidos para que possamos avançar rumo à sala de aula virtual? Evidentemente, trata-se de uma questão cujo tratamento pode ser muito mais amplo que aquele exposto neste relato. Todavia, nossa contribuição reside na afırmação, na reafırmação ou na confirmação de um conjunto de elementos definidores da sala de aula virtual, os quais podem fazer dela o cenário de uma experiência didática única, prazerosa, efetiva, eficaz e totalmente condizente com a dinâmica da sociedade da informação. Esses elementos definidores, dada sua natureza revolucionária, indicam a própria engrenagem do processo de mudança aqui discutido. São eles os conceitos de comunidade de aprendizagem em rede, de trabalho colaborativo virtual, de horizontalização da relação educativa, de materiais didáticos dinâmicos e de mediação pedagógica fundamentada na interatividade. A adoção desses conceitos impõe uma nova dinâmica para a relação educativa virtual, distanciada de procedimentos tradicionais já inoperantes na educação tradicional e de caminhos de massificação da 
formação e de determinismo tecnológico. Afinal, o virtual de que tratamos aqui não é um espaço de abstração, mas de concretude para amparar o trabalho docente a partir desse conjunto de elementos definidores. 0 que está em jogo é a redefinição do espaço educativo. Para tanto, a sala de aula virtual deve potenciali- zar trocas entre seus atores a fim de que eles possam ocupar todos os espaços de cognição propostos pelas NTICE e colocar em sinergia os elementos definidores citados, na medida em que é evidente que a mera inclusão de tecnologias na educação não poderá gerar e sustentar processos de inteligência coletiva.

\section{Referências}

AMORIM, E. S. M. S. A internet como meio de ensino, aprendizagem e divulgação científica no campo da geografia: estudo de caso sobre a implantação do Museu Virtual de Jacobina - Bahia. Dissertação (Mestrado em Tecnologias da Informação e Comunicação em EaD) - Universidade Norte do Paraná, Londrina, 2007.

ANDRADE, J. B. F. A mediação na tutoria on-line: 0 interlace que confere significado à aprendizagem. Dissertação (Mestrado em Tecnologias da Informação e Comunicação em EaD) - Universidade Norte do Paraná, Londrina, 2007.

BARRETO, R. G. Formação de professores, tecnologias e linguagens. São Paulo: Loyola, 2002.

BELLONI, M. L. 0 que é mídia-educação. Campinas: Autores Associados, 2005.

CASTELLS, M. A era da informação: economia, sociedade e cultura. v. 1, 2 e 3. São Paulo: Paz e terra, 1999.

CASTRO, F. Uso de computadores por estudantes está relacionado a pior desempenho. Disponível em: <http://www.inovacaotecnologica.com.br/noticias/noticia.php?artigo=uso-de-computadores-por-estudantes-esta-relacionado-a-pior-desempenho > . Acesso em: 26 jul. 2008.

CASTRO, W. A pedagogia de projetos como estratégia para a formação de professores para uso da informática na educação. Dissertação (Mestrado em Educação) - Universidade de Brasília, Brasília, 2008.

DIAS, A. A. C. Olhar hipertextual: uma perspectiva bakhtiniana da inclusão de imagens na sala de aula. 2007. Disponível em: <http://www.lab-eduimagem.pro.br/frames/seminarios/pdf/aacd.pdf>. Acesso em: 27 jul. 2008.

DWYER, T. et al. Desvendando mitos: os computadores e o desempenho no sistema escolar. Educação \& Sociedade, Campinas, V. 28, n. $101,2007$.

FERNANDES, W. L. Agrorede: estudo exploratório acerca da implementação de uma rede virtual de aprendizagem colaborativa envolvendo as Escolas Agrotécnicas Federais. Dissertação (Mestrado em Tecnologias da Informação e Comunicação em EaD) Universidade Norte do Paraná, Londrina, 2007.

FONSECA, A. P. A internet como meio de comunicação pedagógica de conteúdos dinâmicos em educação ambiental. Dissertação (Mestrado em Educação) - Universidade de Brasília, Brasília, 2005.

GIBSON, W. Neuromancer. São Paulo: Aleph, 1991.

HAGUETTE, T. M. F. Metodologias qualitativas na sociologia. Petrópolis: Vozes, 1985. 
HARASIM, L. M. et al. Redes de aprendizagem: um guia para ensino e aprendizagem on-line. São Paulo: SENAC, 2005.

HILTZ, S. R. Teaching in a virtual classroom. International Journal of Educational Telecommunications, Charlottesville, v. 1, n. 2, p. 185-198, 1995.

INUZUKA, M. A. 0 uso do wiki na educação: um estudo de caso na Faculdade de Educação da Universidade de Brasília. Dissertação (Mestrado em Tecnologias da Informação e Comunicação em EaD) - Universidade Norte do Paraná, Londrina, 2008

KENSKI, V. Tecnologias e ensino presencial e a distância. Campinas: Papirus, 2003.

KUHN, T. S. The structure of scientific revolutions. Chicago: University of Chicago Press, 1970.

LACERDA, R. A. Proposta de um modelo de análise de requisitos para softwares educativos. Dissertação (Mestrado em Educação) - Brasília: Universidade de Brasília, 2007.

LACERDA SANTOS, G. Ciência, tecnologia e formação de professores para 0 ensino fundamental. Brasília: Editora da Universidade de Brasília, 2005.

Formar professores para a educação mediada por tecnologias: elucidação da problemática por meio de seis pesquisas acadêmicas. In: ENCONTRO NACIONAL DE DIDÁTICA E PRÁTICA DE ENSINO, 13., 2006, Recife. Anais... Recife: UFPE, 2006a. v. 1, p. 1-14.

0 computador e o professor: a descoberta de uma nova linguagem? In: ENCONTRO DE PESQUISA EM EDUCAÇÃO DA REGIÃO CENTRO-OESTE, 8., 2006, Cuiabá. Anais... Cuiabá: Provinas, 2006b. v. 1, p. 1-13.

LEMOS, A. Cibercultura: tecnologia e vida social na cultura contemporânea. Porto Alegre: Sulina, 1998.

LÉVY, P. As tecnologias da inteligência: o futuro do pensamento na era da informática. São Paulo: Editora 34, 1993.

0 que é o virtual? São Paulo: Editora 34, 1995.

MACIEL, I. M. Educação a distância. Ambiente virtual: construindo significados. 2002. Disponível em: <http://www.senac.br/ BTS/283/boltec283e.htm>. Acesso em: 27 jul. 2008.

MALVESTITI, M. 0 papel da tutoria em situações de e-learning: um estudo de caso. Dissertação (Mestrado em Educação) Universidade de Brasília, Brasília, 2004.

MINHOLI, M. Ofertas de disciplinas em cursos de pós-graduação lato sensu: estudo de caso da UNIPAR Universidade Paranaense. Dissertação (Mestrado em Tecnologias da Informação e Comunicação em EaD) - Universidade Norte do Paraná, Londrina, 2007.

MOORE, M. Theory of transactional distance. In: KEEGAN, D. (Ed.). Theoretical principles of distance education. London; New York: Routledge, 1993.

MORAES, R. A. Aula virtual e democracia. Tecnologia Educacional, Rio de Janeiro, v. 1, n. 159-160, p. 119-130, 2003.

NEGROPONTE, N. A vida digital. São Paulo: Companhia das Letras, 1995.

OLIVEIRA, E. G. Educação a distância na transição paradigmática. Campinas: Papirus, 2003.

PALLOFF, R. M.; PRATT, K. 0 aluno virtual: um guia para trabalhar com estudantes on-line. Porto Alegre: Artmed, 2005.

PETERS, 0. Didática do ensino a distância. Porto Alegre: Unisinos, 2006. 
PETITTI, D. Overview of methods. In:

Meta-analysis, decision analysis and cost-effectiveness analysis in medicine. New York: Oxford University Press, 1994. p. 15-34.

PIERONI, M. As comunidades de aprendizagem do SERPRO. Dissertação (Mestrado em Educação) - Universidade de Brasília, Brasília, 2004.

PRETTO, N. L. Uma escola sem/com futuro: educação e multimídia. Campinas: Papirus, 1996.

RAMOS, A. L. C. Do texto ao hipertexto. Dissertação (Mestrado em Educação) - Universidade de Brasília, Brasília, 2004.

SENA, V. K. A videoconferência como meio para a formação de competências. Dissertação (Mestrado em Educação) - Universidade de Brasília, Brasília, 2004.

SILVA, M. Sala de aula interativa. Rio de Janeiro: Quartet, 2000.

SOUZA, C. R. Computadores, conhecimento e criatividade: comportamento criativo em crianças do ensino fundamental em situação de aprendizagem mediada por computador. Dissertação (Mestrado em Educação) - Universidade de Brasília, Brasília, 2007.

Recebido em 14.10.09

Aprovado em 09.09.10

Gilberto Lacerda dos Santos é Ph.D. em Educação pela Université Laval, Québec, Canadá, e doutor em Sociologia pela Universidade de Brasília. 